\section{P-66 IDENTIFICATION THROUGH INTEGRATION - INCREASING ACCESS TO PALLIATIVE AND END OF LIFE CARE}

Carol Scholes, Louise Saville-King, Gregory Mary Ann. Hertfordshire Community NHS Trust, Welwyn Garden City, UK

\subsection{6/bmjspcare-2017-00133.66}

Introduction Recognising that someone is entering the last year of life enables access to Palliative and End of Life Care (PEoLC). There is currently under-identification of people in the last year of life.

Aim To enable access to PEoLC through improved identification of the patients known to the Community Trust who are likely to be in the last year of life.

Method In 2014 all Community Trust Specialist Palliative Care Nurses (SPCNs) were integrated into seven community integrated care teams, each covering a population of @100,000. The SPCNs were co-located and managed within those teams. Targeted PEoLC training was delivered to all staff. The SPCNs were supported to improve PEoLC within their locality through weekly Specialist Palliative Care multidisciplinary team meetings, senior nurse leadership, clinical supervision and an internal clinical network.

Results Two of the seven localities have been the most successful in improving identification of people in the last year of life $(57 \%$ increase).

Abstract P-66 Table 1 Number of people identified as in last year of life on System1 two localities (annual snapshot March)

\begin{tabular}{llll}
\hline Year & 2014 & 2015 & 2016 \\
\hline Number & 183 & 223 & 288 \\
\hline
\end{tabular}

These joint reflections from locality manager and SPCN appear key to the improvement:

- Leadership from locality manager on integrating SPCNs

- Weekly locality multidisciplinary clinical meetings to share ideas, opinions, reflect, debrief, give informal education

- Increased visibility improves working relationships

- more conversations, trust, respect,

o team-work, better understanding of roles/workload

- More shared care and joint visits undertaken

- SPCN facilitation of team action learning and clinical supervision

- Offer of uniform to SPCN

Conclusion Integration of community SPCNs can significantly increase access to PEoLC through improved identification of people in the last year of life.

Next steps A comprehensive education programme is supporting staff development with the aim of further improving both access to PEoLC and clinical outcomes.

\section{P-67 PROMOTING DIGNITY AND PATIENT-CENTRED CARE: EVALUATING THE FEASIBILITY OF ENGAGING THE 'PATIENT DIGNITY QUESTION' WITHIN AN ACADEMIC PALLIATIVE CARE UNIT"}

${ }^{1}$ David Cassidy, ${ }^{1}$ Stephen Mason, ${ }^{2}$ Catriona Mayland. 'Marie Curie Palliative Care Institute, University of Liverpool, Liverpool, UK; ${ }^{2}$ Royal Liverpool and Broadgreen University Hospitals NHS Trust

\subsection{6/bmjspcare-2017-00133.67}

Background Patients receiving palliative care, who perceive a diminished sense of dignity, often experience greater symptomatic distress, depression and anxiety. The 'Patient Dignity Question' (PDQ) aims to address this challenge and promote patient centred care by asking 'What do I need to know about you as a person to take the best care of you that I can?' An agreed, transcribed summary of the response(s) are placed in medical and nursing notes. As part of an innovative scholarship programme for undergraduate medical trainees, a protocol for evaluating the feasibility of implementing the PDQ has been designed.

Aim To evaluate the feasibility of implementing the PDQ within an Academic Palliative Care Unit (APCU) in a University Hospital in North West England.

Methods The study uses an exploratory mixed methods design, adapted from existing studies. Suitable participants (inpatients within the APCU; able to provide informed consent) are identified, and consented appropriately by the research team. Feedback questionnaires will assess both patient and staff (HCP) perceptions on the utility and effect of the PDQ. A focus group will explore HCP's perceptions in depth and examine the feasibility of wider implementation of the PDQ. Data on the number of patients approached, agreeing to further information, consented and providing data, will be collected.

Results Data will be collected and analysed during early 2017. Quantitative data will be analysed descriptively and examined for trends. Qualitative data will be thematically analysed in accordance with principles outlined by Braun \& Clarke 2007. Study data will be ready for presentation at conference.

Conclusion There is a developing evidence base on the utility of the PDQ in promoting patient centred care. This student led study, will contribute to the evidence base and provide the groundwork for a future pilot to further assess the efficacy of the PDQ in this environment.

\section{P-68 HOW CONFIDENT ARE FRONT LINE HOSPITAL STAFF IN CARING FOR DYING PATIENTS?}

Jean Potter, Catherine Pye, Roberta Jordan. The Hillingdon Hospital NHS Foundation Trust, Uxbridge, UK

10.1136/bmjspcare-2017-00133.68 
Background Nearly half of all deaths occur in hospital. Most of end of life care (EOLC) is delivered by non specialist staff. Training is variable and usually not mandatory. How confident are front line staff in delivering EOLC?

Methods All inpatient setting healthcare professionals (HCPs) at a general hospital (549 beds) were invited (through email, hospital general bulletin, team meetings) to answer a 10 item questionnaire covering the five Priorities for Care of a Dying Person: their confidence rating on a Likert 1-7 scale about essentials of care and communication.

Scores 5,6 or $7 / 7=$ confident; scores $1-4=$ not confident

All responses were anonymised and inputted via Survey monkey.

Results 181 responses were received: 50/181 ward nursing staff, 24/181 junior doctors, 21/181 HCAs, 20/181 consultants. Consultants were most confident; junior doctors and ward staff least. For all the least confident areas were discussing food and fluids and instigating an individualised care plan (Table 1).

\begin{tabular}{|c|c|c|c|}
\hline & $\begin{array}{l}\text { All\% } \\
(n=181)\end{array}$ & $\begin{array}{l}\text { Junior doctors } \% \\
(n=24)\end{array}$ & $\begin{array}{l}\text { Ward nurses } \% \\
(n=50)\end{array}$ \\
\hline Recognise a dying patient & 65 & 67 & 64 \\
\hline Answer patients questions & 51 & 50 & 42 \\
\hline Discuss DNACPR & 44 & 58 & 44 \\
\hline Discuss food, fluids & 35 & 42 & 34 \\
\hline $\begin{array}{l}\text { Answer relatives } \\
\text { questions }\end{array}$ & 54 & 56 & 44 \\
\hline Individual care planning & 40 & 38 & 32 \\
\hline $\begin{array}{l}\text { Support patient and } \\
\text { family }\end{array}$ & 60 & 46 & 58 \\
\hline Symptom control & 54 & 54 & 52 \\
\hline
\end{tabular}

\section{Conclusions}

- Hands on ward staff report lowest levels of confidence regarding caring for dying patients and their families.

- The least confident area was around discussing provision of food and fluids, which may explain why the NCDAH 2016 found low levels of discussion regarding fluids (with patients: 18\%; with relatives: $39 \%$ of cases)

- This questionnaire can identify specific confidence issues and thus be used to plan bespoke teaching sessions.

\section{P-69 HOSPICE CARE FOR DEPRIVED AREAS - A REVIEW OF THE EQUITY OF HOSPICE CARE IN OUR AREA}

Katie Jerram, P J Morey, Steve Plenderleith. The Rowans Hospice, Purbrook, UK

\subsection{6/bmjspcare-2017-00133.69}

Background In response to the 2015 Marie Curie commissioned document 'Equity in the provision of palliative care in the UK: Review of evidence' which found inequalities in the provision of Palliative Care across a number of domains including social deprivation, I undertook a review of our service in the deprived areas within our area of care.
The Rowans Hospice covers Portsmouth city and South East Hampshire and includes coverage of a number of areas which are within the $20 \%$ most deprived in the country.

Method I identified all patients referred to the inpatient unit or our Hospice at home service from deprived areas over one year, using Office of National Statistics data, Indices of Multiple Deprivation and computerised records. I noted demographics, diagnosis, referrer, time with service, preferred and actual place of death.

Results Compared with the area as a whole, I found that for patients from deprived areas:

- Access to Hospice at Home and inpatient services appears equitable

- Proportion of cancer to non-cancer seems similar

- Average time under the care of Hospice at Home is lower

- Likelihood of being admitted to the Hospice more than once is lower

- Length of inpatient stay is longer

- Chance of a greater than 21 day stay is longer

- PPD is less likely to be recorded

- Dying at home was less likely: but if patients had expressed a wish to die at home they were more likely to achieve this

- More likely than the national average to achieve their PPD

Conclusions The findings of this service review were interesting and broadly positive. Exploring some of the differences found with both service users and professionals would be helpful, and a new initiative (The Living Well Centre) may allow us to connect with those who may not engage with the traditional Hospice model.

\section{P-70 CERVICAL LYMPHADENOPATHY IN YOUNGER ADULTS}

${ }^{1}$ Zakia Sultana, ${ }^{2}$ Sik kim Ang, ${ }^{3}$ Rifat Hasan Mazumder. ${ }^{1}$ Broomfield Hospital, Chelmsford Essex, UK; ${ }^{2}$ RIPAS Hospital,Bandar Seri Begawan, Brunei Darussalam; ${ }^{3}$ Broomfield Hospital, Chelmsford Essex, UK; Supported by: Department of Internal Medicine RIPAS hospital, Bandar Seri Begawan, Brunei Darussalam

\subsection{6/bmjspcare-2017-00133.70}

Introduction Cervical lymphadenopathy is a sign that can be presented in many diseases condition. We are presenting a case of fever with cervical lymphadenopathy due to kikuchi Fujimoto diseases. Kikuchi lymphadenitis is a rare, benign condition of unknown cause usually characterised by cervical lymphadenopathy and fever. While, $40 \%$ of patient with kikuchi disease were initially misdiagnosed as having lymphoma and were consequently over treated with chemotherapy. This pitfall remains an active source of diagnostic error.

Case Mr. Am is a 25 years old Malay man initially admitted under Internal Medicine department with history of fever and neck swelling for more than 2 weeks. During admission, his routine blood tests were normal. Chest $\mathrm{X}$ ray was also clear. Thereafter patient transferred under Palliative medicine unit for the further evaluation and management. His CT-TAP (thorax, abdomen and pelvis) reported as normal study. $\mathrm{He}$ underwent FNAC (fine needle aspiration and cytology) of the cervical lymph node which showed $\mathrm{T}$ cell lymphoma. Although, FNAC report did not clinically correlate. Therefore, for the further workup we performed bone marrow aspiration and trephine. His bone marrow showed leukopenia. We started to treat with steroid which showed some clinical improvement. Mr. Am was seen in the NUH (National University hospital) Singapore for second opinion. His working 